\title{
Clinical Trial Management
}

National Cancer Institute

\section{Source}

National Cancer Institute. Clinical Trial Management. NCI Thesaurus. Code C115766.

The conducting, guidance, regulation, direction, or supervision of a clinical trial. 